\title{
University of Toronto Lupus Clinic Turns 40
}

DAFNA D. GLADMAN, MD, FRCPC, Professor of Medicine, University of Toronto, Senior Scientist, Toronto Western Research Institute, Co-Director, University of Toronto Lupus Clinic; Deputy Director, Centre for Prognosis Studies in The Rheumatic Diseases; MURRAY B. UROWITZ, MD, FRCPC, Professor of Medicine, University of Toronto; Senior Scientist, Toronto Western Research Institute; Director, University of Toronto Lupus Clinic and Centre for Prognosis Studies in the Rheumatic Diseases, Toronto Western Hospital, Toronto, Canada. Address correspondence to Dr. D.D. Gladman, Centre for Prognosis Studies in the Rheumatic Diseases, Toronto Western Hospital, 399 Bathurst Street, 1E-410B, Toronto, Ontario M5T 2S8. E-mail: dafna.gladman@utoronto.ca. J Rheumatol 2012;39:1074-7; doi:10.3899/jrheum.111581

The University of Toronto Lupus Clinic at the Toronto Western Hospital celebrated its 40th anniversary April 2, 2011. Great cause for celebration, particularly, since more than 1600 patients have been registered in what is one of the largest databases of lupus patients in the world - probably the only one following patients prospectively according to a standard protocol since 1970 - it was also an opportunity to pay tribute to Dr. Murray Urowitz, founder and director of the clinic, and to his contributions to lupus care and research.

This milestone celebration took the form of a symposium, held April 2, 2011; several current and previous trainees were invited to give oral presentations on their current work as it relates to their training at the Lupus Clinic, while others submitted abstracts for poster presentations.

\section{Accomplishments of the Lupus Clinic}

By way of introduction, Dafna Gladman reviewed the achievements of the University of Toronto Lupus Clinic since its inception.

Murray Urowitz began the Lupus Clinic in 1970 to study the correlation between clinical and serological activity in systemic lupus erythematosus (SLE). A standardized data retrieval form was developed including demographic features, disease-related features, and laboratory tests and therapies. Of note, there was no computer! Despite the lack of computer assistance, several seminal observations were made. These include the bimodal mortality pattern of SLE and the recognition that patients with SLE were at risk for accelerated atherosclerosis ${ }^{1}$. The impact of disease and comorbidities in the first 110 patients registered at the clinic were then highlighted ${ }^{2}$. A new observation of nail lesions in SLE was described ${ }^{3}$.

By 1977, it became clear that computerization of the data would greatly facilitate research. During the first phase data were entered on the University of Toronto mainframe computer using punch cards. In 1980 the first desktop computer was introduced; data were entered using SAS Editor. Subsequently, in 1990, information was transferred to an ORACLE database allowing keyboard data entry. Data retrieval forms, which were developed and updated reflecting the ORACLE data entry format, included updates to comorbidities. This new format allowed us to make a number of observations, summarized in a review of the clinic published in $2005^{4}$.

In order to more accurately follow patients with lupus, several disease activity instruments were developed, validated, and modified, including the Lupus Activity Criteria Count, the Systemic Lupus Erythematosus Disease Activity Index (SLEDAI) and its modifications [SLEDAI-2K, SLEDAI 30 days, and adjusted mean SLEDAI (AMS) $]^{4,5}$. Addressing the issue of response to therapy, flare based on SLEDAI-2K was defined, and more recently a responder index based on a $50 \%$ response in SLEDAI-2K descriptions $^{6}$, the SLEDAI Responder Index 50 (SRI-50), was derived $^{7}$.

Further studies from the Lupus Clinic reported organspecific clinical features and outcomes including neuropsychiatric lupus, technetium brain scan and single-photon-emission computed tomography scan in SLE, lupus retinopathy, neurocognitive dysfunction in patients with inactive SLE, the role of kidney biopsy, and the occurrence of osteoporosis, vitamin D deficiency in SLE and osteonecrosis in SLE SL, $^{4,9,10}$.

Having recognized the importance of accelerated atherosclerosis in SLE, we identified the role of persistent hypercholesterolemia in the development of coronary artery events in patients with SLE. We further studied the risk factors for atherosclerosis in women with SLE and documented that coronary artery events occurred more commonly among women with SLE than controls, and confirmed that SLE itself was a risk factor for the development of accelerated atherosclerosis in $\mathrm{SLE}^{11}$. We demonstrated that there has been improvement in survival over the past 4 decades, although people with lupus are still at risk for mortality 3 times that of the otherwise healthy population ${ }^{12}$. We further demonstrated that myocardial perfusion scanning is strongly and independently predictive of coronary artery disease in SLE ${ }^{13}$.

Laboratory tests studied demonstrated that the use of the Farr assay to detect anti-DNA antibodies is more reliably related to disease activity than the ELISA method ${ }^{14}$. We demonstrated the variability of high-sensitivity C-reactive protein (hsCRP) measurements in patients with lupus ${ }^{15}$. We

Personal non-commercial use only. The Journal of Rheumatology Copyright @ 2012 . All rights reserved. 
identified a unique interferon signature based on gene expression profiles among patients with SLE and related it to disease activity ${ }^{16}$. We also related killer immunoglobulinlike receptor genes to $\mathrm{SLE}^{17}$.

In the late 1970s we described a subset of patients with serologically active clinically quiescent lupus (SACQ). Further studies confirmed the existence of this group but failed to identify a prognostic factor for the development of $\mathrm{SACQ}^{18}$. Investigation on this subset of patients is continuing. We have also demonstrated that a small group of patients with SLE sustain a complete remission, without evidence of disease activity and on no medications ${ }^{19}$.

The Lupus Clinic has thus demonstrated exemplary patient care and has performed clinical practice research, with important contributions to lupus research totaling 212 peer-reviewed publications. Many of these contributions have actually altered practice. Moreover, a large number of physicians and other professionals have been trained at the clinic.

\section{Scientific Symposium - SLE Update}

The symposium included several podium presentations from previous Lupus Fellows who presented work done since completing their training at the clinic.

Ian Bruce, Manchester, England. Dr. Bruce made a presentation entitled Accelerated Atherosclerosis in SLE and Rheumatoid Arthritis: the Manchester View. Dr. Bruce began studying atherosclerosis in SLE while a clinical research fellow at the Lupus Clinic 1996-1998. He continued research in this area and is now Professor of Rheumatology at the Arthritis Research UK Epidemiology Unit, School of Translational Medicine, University of Manchester, and The Kellgren Centre for Rheumatology, Manchester Royal Infirmary. It has been noted at the Manchester Clinic that patients with SLE have impaired endothelial function as well as a higher burden of carotid plaque, most noticeably among young women. SLE women also show evidence of dysfunctional endothelial progenitor cells, which may contribute to impaired capacity for vascular repair.

Lai-Shan Tam, Hong Kong, China. Dr. Tam, who trained at the Lupus Clinic 1998-1999, has continued her studies in SLE upon returning to her native Hong Kong, where she is Professor, Department of Medicine and Therapeutics, The Chinese University of Hong Kong. She reported that the prevalence of cervical neoplasia is increased 3-4 fold in patients with SLE, which is associated with the use of cyclophosphamide and persistent human papilloma virus (hr-HPV) infection. hr-HPV infections may play a predominant role in downregulating the expression of Toll-like receptor-7 (TLR-7) and TLR-9 in the cervical epithelial cells of patients with SLE, resulting in a higher prevalence of persistent infection. TLR-7 agonist is effective in trigger- ing production of proinflammatory cytokines, enhancing viral clearance in subjects with high-risk HPV infection.

Mahmood Abu-Shakra, Beer Sheva, Israel. Dr. Abu-Shakra trained at the University of Toronto Rheumatology program 1991-1994, the last year as a Geoff Carr Lupus Fellow. He is Professor of Medicine and Head, Rheumatic Diseases Unit, Soroka Medical Center and Ben-Gurion University, Beer-Sheva, Israel. His presentation focused on quality of life, coping, and depression in SLE. He showed that lupus patients had poorer quality of life than normal controls. Education, age, SLICC damage index (SLE International Collaborating Clinics), and sense of coherence are independently associated with quality of life of women with SLE. There is a reciprocal longitudinal relationship between depression and illness intrusiveness in SLE.

John Hanly, Halifax, Canada. Dr. Hanly presented on classification, epidemiology, and outcome of neuropsychiatric SLE. Dr. Hanly was a Lupus Fellow in 1984-1985. He is currently Professor of Medicine and Pathology, and Director, Dalhousie Lupus Clinic, Division of Rheumatology, Department of Medicine and Department of Pathology, Capital Health and Dalhousie University, Halifax, Nova Scotia. He reported that nervous system disease in SLE consists of common and rare events and that the American College of Rheumatology case definitions for neuropsychiatric (NP) syndromes provide a platform for the clinical characterization of these events in patients with SLE. Attribution of NP events suggests that the majority are not due to SLE, but regardless of attribution, NP events are associated with a lower health-related quality of life.

John Esdaile, Vancouver, Canada. Dr. Esdaile attended the Lupus Clinic in 1975-1976. He is currently Professor of Medicine, University of British Columbia, and Arthur J.E. Child Chair in Rheumatology Research, University of Calgary; and Scientific Director, Arthritis Research Centre of Canada. In presenting a provocative discussion, Patient Registries - Are They Worth It?, he suggested that advantages of registries are that they reflect the real world as compared with randomized controlled trials; moreover, with good followup, registries can provide data on outcomes and adverse events beyond the duration of trials. He then outlined the many difficulties inherent in longterm observational studies.

Proton Rahman, St. John's, Canada. Dr. Rahman trained at the Lupus Clinic 1996-1999 and is currently Professor of Medicine, Division of Rheumatology, Memorial University, St. John's. His presentation, Potential Advantages and Limitations of Incorporating Recent Genetic Discoveries in a Lupus Clinic, provided an overview of the more than 30 genes already identified in SLE and how they relate to sev-

Personal non-commercial use only. The Journal of Rheumatology Copyright (C) 2012. All rights reserved. 
eral key biologic pathways. He also provided a template to better understand new genetic associations.

Mandana Nikpour, Melbourne, Australia. Dr. Nikpour attended the Lupus Clinic in 2005-2009 and was enrolled in a $\mathrm{PhD}$ program. She discussed risk factors for atherosclerosis in SLE, a topic of her PhD thesis, which she had defended only the day before. Dr. Nikpour is Senior Lecturer, Department of Medicine, University of Melbourne; and Rheumatologist, St. Vincent's Hospital, Melbourne. Dr. Nikpour discussed the role of hsCRP and lipids, and suggested cutpoints to assess cardiovascular risk among patients with SLE. She also discussed emerging concepts in coronary artery disease risk evaluation in SLE and the role of cumulative exposure to dynamic risk factors.

Christian Pineau, Montreal, Canada. Dr. Pineau trained at the Lupus Clinic in 2000-2001. He is currently Assistant Professor, Department of Medicine, McGill University, Montreal, and Co-Director and Consultant, Division of Rheumatology, McGill University Health Centre Lupus Clinic. His presentation, The Wolf Who Bit My Heart: Non-Atherosclerotic Cardiac Involvement in SLE, covered the large number of possibilities of heart involvement in SLE. He is particularly interested in conduction abnormalities and their relationship to anti-Ro antibodies.

Zahi Touma, Lupus Clinic, Toronto, Canada. A trainee at the Lupus Clinic since 2008, Dr. Touma is also enrolled in a $\mathrm{PhD}$ program. In his presentation, Responder Indices in SLE, he reviewed existing indices to assess disease activity in SLE and highlighted issues that have arisen in recent drug trials. Dr. Touma then introduced the SRI-50, which he has developed and validated as part of his $\mathrm{PhD}$ project. He demonstrated the potential utility of the SRI-50 as an outcome measure in future drug trials in SLE.

The symposium also featured posters presented by current and previous fellows attending the Lupus Clinic.

Debra Dye-Torrington. Dr. Dye-Torrington, a current trainee, presented 2 posters. The first evaluated the correlation between urine protein to creatinine ratio $(\mathrm{P} / \mathrm{C})$ in an untimed urine collection and 24-hour total protein excretion in patients with lupus nephritis. She showed that there is a poor correlation between spot $\mathrm{P} / \mathrm{C}$ ratios and 24-hour urine protein excretion at levels of proteinuria of 2 grams or more. She concluded that $\mathrm{P} / \mathrm{C}$ ratios should not be used to monitor protein excretion in patients with lupus nephritis. In her second poster Dr. Dye-Torrington reported on time to development of nephritis in patients with SLE. She showed that renal disease in patients with lupus nephritis does not necessarily occur at inception. The presence of dsDNA antibodies was the only predictor of development of renal disease.
Carolina Landolt-Marticorena. Dr. Landolt-Marticorena, who trained at the Lupus Clinic 2006-2007 and is currently on staff, reported on clinical utility of changes in cyto/chemokines as markers of disease activity in SLE. She concluded that IP-10, monocyte chemoattractant protein-1, and soluble vascular cell adhesion molecule-1 may be useful biomarkers to monitor disease activity in SLE. She also described urinary cyto/chemokines correlated with the histopathology of SLE. She showed that urinary elevation in selected cyto/chemokines effectively discriminates between active and chronic renal lesions. The elevation of $\geq 2$ analytes was sufficient to identify proliferative lesions.

Pnina Langevitz. Dr. Langevitz, Chaim Sheba Medical Centre, Tel Hashomer, Israel, who trained at the Lupus Clinic in 1999, presented MEFV Mutation Carriage and SLE: Possible Protection from Severe Renal Involvement. She showed that the familial Mediterranean fever $M E F V$ gene mutation carriage may be associated with a milder SLE disease phenotype and specifically may confer protection from severe renal involvement.

Amanda Steiman. Dr. Steiman, a current Goeff Carr Lupus Fellow, presented a series of 4 posters related to serologically active clinically quiescent lupus (SACQ), work currently pursued at the Lupus Clinic. In the first poster, Prolonged SACQ: Clinical and Serologic Features, she showed that patients with SACQ are a small but clinically important group within the SLE population. Although 59\% of patients with SACQ experience flare, they do so after a median of 3 years. In a second poster, predictors of flare were sought in the SACQ cohort; it was found that elevated anti-dsDNA antibodies and low complement were not associated with occurrence of flare among patients with SACQ. The third poster described the outcomes in patients with SLE with and without a prolonged SACQ period. Patients with a prolonged period had significantly less damage accrual over 5 to 10 years compared to matched SLE controls. This supports the practice of active surveillance without treatment (with steroids or immunosuppressives) during the SACQ period. The fourth poster described a search for novel predictors for flare among patients with SACQ. In this small pilot study neither anti-chromatin nor anti-dsDNA antibody levels were predictive of flare in SACQ patients. Alternative serum biomarkers must be sought.

Sergio Toloza. Dr. Toloza is a recent graduate from the Lupus Program who has returned to his native Argentina. He presented on International Cross Cultural Validation of the Spanish LupusPRO. LupusPRO is a patient-reported outcome measure developed specifically from and for male and female patients with SLE. Fully validated in English within the USA, a Spanish version of LupusPRO was validated by Dr. Toloza and his group.

Personal non-commercial use only. The Journal of Rheumatology Copyright @ 2012. All rights reserved. 
Arthur Weinstein. Trained at the Lupus Clinic in 1976, Dr. Weinstein is now Associate Chairman of the Department of Medicine and Director of the Division of Rheumatology at Washington Hospital Center, Washington, DC, USA. He reported a preliminary study suggesting that SLE patients with persistently low C3 and normal C4 levels appear to have less active disease than those with low $\mathrm{C} 3$ and low $\mathrm{C} 4$ levels. The immunological pathophysiology underlying the C3 hypocomplementemia in these patients is unknown.

Bevra Hahn. Dr. Hahn, from Los Angeles, CA, USA, was the keynote speaker on the topic Treatment of SLE in 2011. Dr. Hahn trained with Murray Urowitz at Johns Hopkins Hospital and like Dr. Urowitz has devoted her career to the study of lupus. Dr. Hahn emphasized that clinicians treating patients with SLE have 3 goals: to (1) induce improvement; (2) maintain improvement; and (3) minimize damage caused by ongoing disease and treatments. She described recent advances using mycophenolate mofetil, cyclophosphamide, and belimumab in inducing improvement, and the role of mycophenolate and azathioprine in maintenance therapy. Dr. Hahn also described the use of antimalarial medications to minimize use of corticosteroids, angiotensin-converting enzyme inhibitors, cholesterol-lowering medications, and lifestyle change to minimize cardiovascular and renal damage in SLE. The results of these "modern" strategies should lead to better survival and better quality of life for patients with SLE.

The day of celebration concluded with a gala dinner, attended by over 200 people, at which it was announced that $\$ 465,000$ had been raised towards the Murray Urowitz Lupus Fellowships.

\section{REFERENCES}

1. Urowitz MB, Bookman AAM, Koehler BE, Gordon DA, Smythe HA, Ogryzlo MA. The bimodal mortality pattern of systemic lupus erythematosus. Am J Med 1976;60:221-5.

2. Lee P, Urowitz MB, Bookman AAM, Koehler BE, Smythe HA, Gordon DA, et al. SLE: A review of 110 cases with particular reference to lupus nephritis, CNS manifestations, infections, aseptic necrosis and prognosis. Q J Med 1977;46:1-32.

3. Urowitz MB, Chalmers A, Gladman DD, Ogryzlo MA. Nail lesions in SLE. J Rheumatol 1978;5:441-7.

4. Urowitz MB, Gladman DD. Contributions of observational cohort studies in systemic lupus erythematosus: The University of Toronto Lupus Clinic experience. Rheum Dis Clin N Am 2005;31:211-21.
5. Touma Z, Urowitz MB, Gladman DD. SLEDAI-2K for a 30-day window. Lupus 2010;19:49-50.

6. Gladman DD, Urowitz MB, Kagal A, Hallett D. Accurately describing changes in disease activity in SLE. J Rheumatol 2000;27:377-9.

7. Touma Z, Gladman DD, Ibañez D, Urowitz MB. Development and initial validation of SLEDAI-2K (Systemic Lupus Erythematosus Disease Activity Index 2000) Responder Index-50 (SRI-50). J Rheumatol 2011;38:275-84.

8. Pineau CA, Urowitz MB, Fortin F, Ibañez D, Gladman DD. Osteoporosis in SLE: Factors associated with referral for bone mineral density studies, prevalence of osteoporosis and factors associated with reduced bone density. Lupus 2004;13:1-6.

9. Toloza SM, Cole DE, Gladman DD, Ibañez D, Urowitz MB. Vitamin D insufficiency in a large female SLE cohort. Lupus 2010;19:13-9.

10. Prasad R, Ibañez D, Gladman DD, Urowitz MB. The role of non-corticosteroid related factors in osteonecrosis (ON) in SLE: A nested case-control study of inception patients. Lupus 2007; 16:157-62.

11. Goldberg RJ, Urowitz MB, Ibañez D, Nikpour M, Gladman DD. Risk factors for development of coronary artery disease in women with systemic lupus erythematosus. J Rheumatol 2009;11:2454-61.

12. Urowitz MB, Gladman DD, Tom BDM, Ibañez D, Farewell VT. Changing patterns in mortality and disease outcome for patients with systemic lupus erythematosus. J Rheumatol 2008;35:2152-8.

13. Nikpour M, Gladman DD, Ibañez D, Bruce IN, Burns RJ, Urowitz MB. Myocardial perfusion imaging in assessing risk of coronary events in patients with systemic lupus erythematosus. J Rheumatol 2009;36:288-94.

14. Neogi T, Gladman DD, Ibañez D, Urowitz MB. Anti-dsDNA antibody testing by Farr and ELISA techniques are not equivalent. J Rheumatol 2006;33:1785-8.

15. Nikpour M, Ibañez D, Gladman DD, Urowitz MB. Variability and correlates of high sensitivity C-reactive protein in systemic lupus erythematosus. Lupus 2009;18:966-73.

16. Nikpour M, Dempsey AA, Urowitz MB, Gladman DD, Barnes DA. Association of a gene expression profile from whole blood with disease activity in systemic lupus erythematosus. Ann Rheum Dis 2008;67:1069-75.

17. Toloza S, Pellett F, Ibañez D, Chandran V, Urowitz MB, Gladman DD. Association of Killer cell immunoglobulin-like receptors (KIR) with vascular events and autoantibodies in SLE. Lupus 2008;17:793-8.

18. Steiman AJ, Gladman DD, Ibañez D, Urowitz MB. Prolonged serologically active clinically quiescent (SACQ) systemic lupus erythematosus: Frequency and outcome. J Rheumatol 2010;37:1822-7.

19. Urowitz MB, Feletar M, Bruce I, Ibañez D, Gladman DD. Prolonged remission in systemic lupus erythematosus. J Rheumatol 2005;32:1467-72. 